\section{(6) OPEN ACCESS}

\title{
Effect of autologous adipose-derived mesenchymal stem cell therapy in the treatment of acromioclavicular joint osteoarthritis
}

\author{
Julien Freitag, ${ }^{\oplus 1,2,3}$ James Wickham, ${ }^{1}$ Kiran Shah, ${ }^{3}$ Abi Tenen ${ }^{2,3,4,5}$
}

\begin{abstract}
${ }^{1}$ School of Biomedical Science, Charles Sturt University, Orange, New South Wales, Australia ${ }^{2}$ Melbourne Stem Cell Centre, Box Hill North, Victoria, Australia ${ }^{3}$ Magellan Stem Cells, Box Hill North, Victoria, Australia ${ }^{4}$ Monash University School of Primary Health Care, Monash University, Notting Hill, Victoria, Australia

${ }^{5}$ Vision Eye Institute, Melbourne, Victoria, Australia
\end{abstract}

Correspondence to

Associate Professor Julien Freitag,

julien.freitag@mscc.com.au

Accepted 5 January 2019

\section{SUMMARY}

The aim of this case report is to evaluate the efficacy of mesenchymal stem cell (MSC) therapy in the treatment of small joint osteoarthritis (OA). Acromio-clavicular (AC) joint $O A$ is an under-diagnosed and yet frequent source of shoulder pain. MSCs have shown evidence of benefit in the treatment of knee OA. This is the first report to describe the use of MSC therapy in OA of the upper limb. A 43-year-old patient presents with painful AC joint OA and undergoes MSC therapy. The patient reported pain and functional improvement as assessed by the Disability of Arm, Shoulder and Hand Score and Numeric Pain Rating Scale. Imaging at 12 months showed structural improvement with reduction in subchondral oedema, synovitis and subchondral cysts. This case is the first to show the benefit of MSC therapy in the treatment of small joint arthropathy and also of the upper limb. Trial registration number: Australian New Zealand Clinical Trials Registry (ACTRN12617000638336).

\section{BACKGROUND}

The acromioclavicular (AC) joint can be a frequent but under-diagnosed source of shoulder pain. Zanca, in a case cohort of 1000 patients with 'shoulder pain', described an incidence of AC joint pathology of $12.7 \% .{ }^{1}$ An observational study using MRI demonstrated arthritic changes in up to $48 \%$ of the older patient cohort. ${ }^{2}$

The AC joint is a diarthrodial joint with a fibrocartilaginous meniscal disc separating the distal clavicle and the acromion. It is stabilised by the capsule, superior and inferior AC ligaments and two coraco-clavicular ligaments (conoid and trapezoid). The AC joint can be prone to injury not only due to its relationship to the shoulder girdle and its position predisposing it to direct trauma, but also due to the biomechanics of the shoulder girdle that require large loads to be transmitted across the small surface area of the joint.

Causes of AC joint pain include primary osteoarthritis (OA), post-traumatic OA and distal clavicular osteolysis (DCO). Primary OA is accepted as a degenerative and progressive age-related condition with changes often presenting by the fourth decade of life. ${ }^{3}$ Post-traumatic OA is a sequelae of AC joint injury such as AC separation or distal clavicular fractures leading to degenerative changes. DCO was first described in 1936 and can be separated into both traumatic and atraumatic. ${ }^{4}$ While the pathogenesis of DCO is often debated it has become more commonly accepted as a result of repetitive micro-trauma with resultant underlying subchondral micro-fractures and failed attempts at repair.

The conservative management of $\mathrm{AC}$ joint pain involves avoidance of provocative manoeuvres and activities, use of simple analgesics and non-steroidal anti-inflammatories. Taping may be trialled to limit range of motion and reduce compression or traction forces across the joint. Injection of local corticosteroids is considered if the patient fails conservative management though it is accepted the corticosteroids may only provide short-term relief. ${ }^{56}$ Corticosteroid injections in combination with local anaesthetic are often useful as a diagnostic tool in confirming the source of pain to be the AC joint.

For those patients who fail conservative management and have persistent pain, the accepted surgical approach is to perform a distal clavicular excision. This technique has been shown to reproducibly result in symptomatic relief and return patients to previous levels of activity. ${ }^{7}$ Both an open or arthroscopic approach may be chosen with both procedures showing comparable long-term outcomes; though arthroscopic resection may have a faster return to previous activities.

Complications that have been described following distal clavicular excision include inadequate resection, joint instability and shoulder weakness. ${ }^{8}$ These complications have been noted using both open and arthroscopic approaches. Instability and resultant weakness are thought to be related to loss of normal AC ligament integrity. ${ }^{9-11}$

The ability of mesenchymal stem cells (MSCs) to differentiate into both osteoblasts and chondrocytes has seen them explored as a cellular therapy for tissue repair and regeneration in OA. ${ }^{12-14}$ However, despite their observed multipotency, it is now more commonly accepted that their mechanism of action involves cell to cell and paracrine signalling rather than direct differentiation. ${ }^{15}$

There is a growing body of research for the use of biological therapies including MSC therapy in the treatment of symptomatic knee OA. The use of MSC impregnated biological scaffolds and direct intra-articular MSC injections have shown promise in both pre-clinical and clinical studies. ${ }^{16-20}$ However, despite this emerging evidence, there is a paucity of literature on the benefits of MSC therapy in small joints or that of the upper limb. The noted 


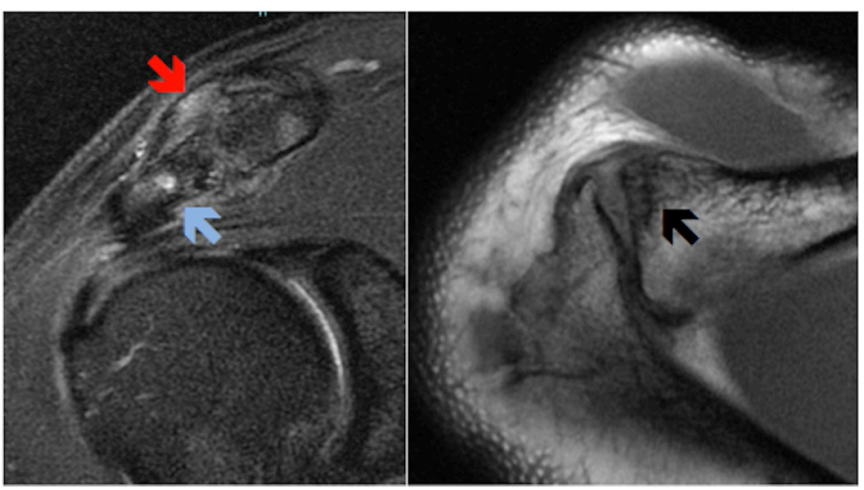

Figure 1 Pre-treatment coronal and axial MRI of the shoulder showing evidence of AC joint arthritis with with capsular thickening and joint inflammation (red arrow); florid clavicular and acromial boney oedema (blue arrow); and distal clavicular subcortical cyst formation (black arrow).

potential complications of surgical intervention for symptomatic AC joint pathology suggests that MSC therapy may be a plausible alternative treatment if research indicates reproducible benefit/efficacy.

The aim of this case study was to assess the efficacy of autologous MSC therapy in the treatment of AC joint arthropathy in comparison to previously published results involving large weight bearing joints such as the knee. This case study forms part of a broader ethics approved and registered case series on the effect of MSC therapy in arthritis.

\section{CASE PRESENTATION}

A 43-year-old man presented with a painful right shoulder. He had no prior history of injury. The patient was unable to comfortably lift their arm above shoulder height and this significantly impacted on his work and also his recreational sporting pursuits which included swimming and weight lifting. The patient was otherwise well with no relevant medical history.

The patient had previously seen a sports physician and undergone an ultrasound guided corticosteroid injection with complete resolution of pain. Unfortunately, he had recurrence of symptoms shortly after the injection.

MRI of the shoulder showed evidence of advanced AC joint OA. Loss of joint space, capsular thickening, joint inflammation, distal clavicular and acromial subcortical cyst formation and florid clavicular and acromial boney oedema were observed (figure 1).

The patient failed to improve with use of simple analgesia (paracetamol and non-steroidal anti-inflammatories) and activity modification. After careful consideration, and as the patient wished to delay or prevent surgery, the patient commenced autologous adipose-derived MSC (AdMSC) therapy.

The patient received formal written information regarding the use of and relative risks that may be associated with MSC therapy. Prior to commencement of treatment, the patient completed formal written consent.

\section{INVESTIGATIONS}

MRI of the right shoulder showed evidence of severe AC joint OA with loss of joint space, capsular thickening, joint inflammation/synovitis, distal clavicular and acromial subcortical cyst formation and florid clavicular and acromial boney oedema (figure 1). A repeat MRI was performed at 12 months post-commencement of AdMSC therapy (figure 2).

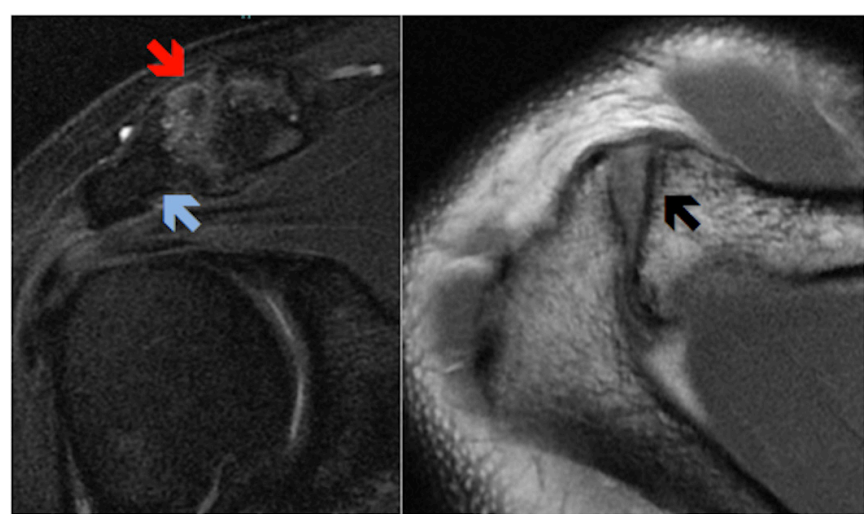

Figure 2 Post-treatment coronal and axial MRI showing improvement in features of synovitis with reduced joint effusion (red arrow); reduction in subchondral boney oedema (blue arrow) and significant resolution of subchondral cysts (black arrow).

\section{TREATMENT}

\section{Autologous adipose-derived stem cell preparation}

Harvest procedure

Adipose tissue has been shown to be a rich source of autologous MSCs, with AdMSCS having an observed chondrogenic potential. ${ }^{21-23}$

The patient underwent an abdominal lipoharvest procedure which has previously been described in past publications. $^{24}{ }^{25}$ Following the infiltration of $200 \mathrm{~mL}$ of tumescent fluid (comprising of $30 \mathrm{~mL}$ of $2 \%$ lignocaine, $1 \mathrm{~mL}$ of $1: 1000$ epinephrine and $1 \mathrm{~mL}$ of $8.4 \%$ bicarbonate suspended in normal saline to a total volume of $1000 \mathrm{~mL}$ ), and using a hand held manual suction technique (a $3 \mathrm{~mm}$ lipoaspirate cannula connected to a $20 \mathrm{~mL}$ syringe), $40 \mathrm{~mL}$ of lipoaspirate was collected. The lipoaspirate was transferred directly from theatre via an air lock to a clean room laboratory on site (Magellan Stem Cells, Melbourne, Australia).

Isolation and expansion of mesenchymal stem cells

Isolation and expansion of autologous AdMSCs was performed within a clean room laboratory with equivalent of $>$ ISO 5 air quality and Class II biological safety cabinets. The process of isolation and expansion has been previously described. ${ }^{24-26}$

At completion of isolation and expansion, the AdMSCs were suspended in a clinical grade MSC cryoprotectant media and cryopreserved using a validated control rate freezing method. ${ }^{242728}$

\section{Characterisation and sterility testing}

AdMSCs were characterised as per criteria established by the International Society of Cellular Therapy. ${ }^{29}$ Flow cytometry fluorescent activated cell sorting (FACS) analysis assessed for the presence of MSC surface markers CD90, CD73 and CD105 and absence of haematopoietic surface markers CD14, CD19, CD34 and CD45 (table 1).

At completion of isolation and expansion independent sterility testing for microbial growth/contamination was performed.

\section{AdMSC carrier media preparation}

Autologous conditioned serum was chosen as a carrier media in which to suspend the AdMSCs at time of injection. The combination of MSCs with a blood-derived carrier media has been previously proposed to assist in the expression of collagen Type II and reduce chondrocyte apoptosis. ${ }^{30}$ Growth factors expressed 
Table 1 Fluorescent activated cell sorting surface marker analysis showing results consistent with mesenchymal stem cells as per the International Society of Cellular Therapy guidelines

\begin{tabular}{|c|c|c|c|c|c|c|c|}
\hline & \multicolumn{3}{|c|}{ Positive markers } & \multicolumn{4}{|c|}{ Negative markers } \\
\hline & CD90+ve & CD73+ve & CD105+ve & CD14+ve & CD19+ve & CD34+ve & CD45+ve \\
\hline Percentage & 97.15 & 98.84 & 95.16 & 0.59 & 0.05 & 0.69 & 0.37 \\
\hline
\end{tabular}

in ACS including Transforming Growth Factor Beta1 and basic Fibroblast Growth Factor (bFGF) have been shown to assist in migration of stromal cells to the site of injury. ${ }^{30}$

A total of $27 \mathrm{~mL}$ of whole blood was withdrawn from the patient via venepuncture of an ante-cubital vein and collected in $3 \times 9 \mathrm{~mL}$ sterile S-Monovette clotting activator tubes (Starstedt, Numbrecht, Germany). The tubes were incubated for 24 hours at $38^{\circ} \mathrm{C}$. After the period of incubation, the tubes were then centrifuged at $1000 \mathrm{rpm}$ for $5 \mathrm{~min}$ with separation of the plasma and cellular components. The plasma layer was removed and filtered through a 0.2 -micron syringe filter (PALL, New York, USA) resulting in a sample of ACS.

\section{Injection method and protocol}

AdMSCs were taken out of cryopreservation and thawed in a sterile water bath with the cyroprotectant media removed using both repeat centrifugation and washing in chilled phosphate buffered saline. The resultant cell pellet was re-suspended in ACS to a total of $1 \mathrm{~mL}$. Cell viability and number was confirmed using a Muse Cell Analyser (Merck, Millipore, USA).

AdMSC therapy was administered at baseline and at 5 months (Week 22).

The patient received a total of 10 million ADMSCs (viability 95.9\%) on Day 1 and a total of 8 million AdMSCs (viability 98.3\%) at 5 months (Week 22).

Under ultrasound guidance and sterile conditions, a 22 gauge needle was placed into the AC joint using a lateral approach. The AdMSCs were injected with no prior infiltration of local anaesthetic.

\section{Analysis}

The following validated outcome questionnaires were completed prior to treatment and prospectively post-treatment:

1. Numeric Pain Rating Scale: The patient rated his shoulder pain over the previous week on a scale of $0-10$. The NPRS has been previously validated for using in patients with OA. ${ }^{31}$

2. Quick disability of arm, shoulder and hand (QuickDASH): The DASH outcome measure is a validated quality of life measure used to assess disability secondary to upper limb

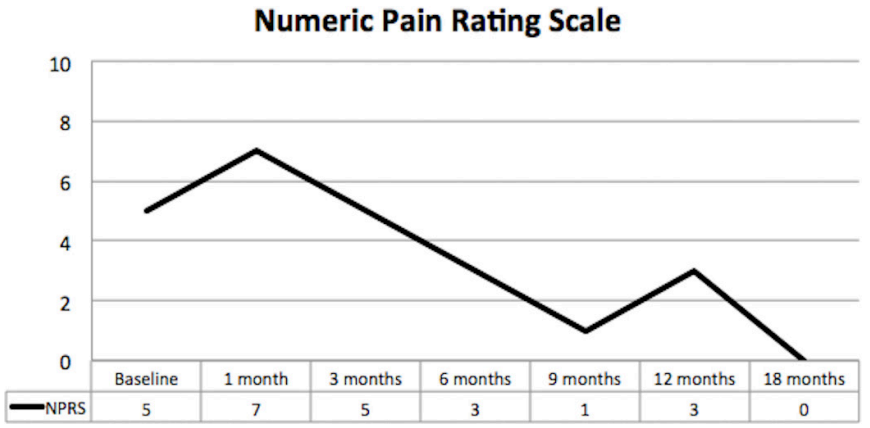

Figure 3 Numeric Pain Rating Scale showing clinically significant reduction in pain throughout the period of data collection. complaints. $^{32}$ In this case study, the QuickDASH is used which is a two-part assessment consisting of a Disability Score and a Sport Score. The score ranges from 0 (no disability) to 100 (most severe disability). An improvement of 10 points is considered a minimal clinically important difference. ${ }^{33}$

\section{OUTCOME AND FOLLOW-UP}

Pain and functional outcome

The patient had consistent improvement in pain throughout follow-up with the NPRS improving from 5 at baseline to 0 at completion of data collection at 18 months (figure 3 ).

QuickDASH scores at baseline indicated moderate functional impairment. Both the QuickDASH Disability and Sport scores improved consistently from baseline to final follow-up (figure 4). The DASH sport score achieved a minimal clinically important difference as early as 1 month after commencement of therapy.

\section{Structural outcome}

Repeat MRI imaging of the shoulder at 12 months showed resolution of synovitis and joint effusion, resolution of subchondral oedema of both the distal clavicle and acromion and improvement in subchondral cyst size (figure 2).

\section{Complications and adverse events}

The patient observed a self-limiting flare up in discomfort following each AdMSC injection which lasted 1-3 days. This did not require additional analgesic medication and did not affect their daily activities and was considered a mild adverse event.

\section{DISCUSSION}

This case study indicates the successful management of symptomatic AC joint OA with the novel method of intra-articular AdMSC therapy. The patient had previously failed to improve with conventional conservative therapy including use of simple analgesics and corticosteroid injections.

Current management of symptomatic AC joint arthropathy or DCO which fails to respond to conservative therapy includes

Disability of Arm Shoulder and Hand Score

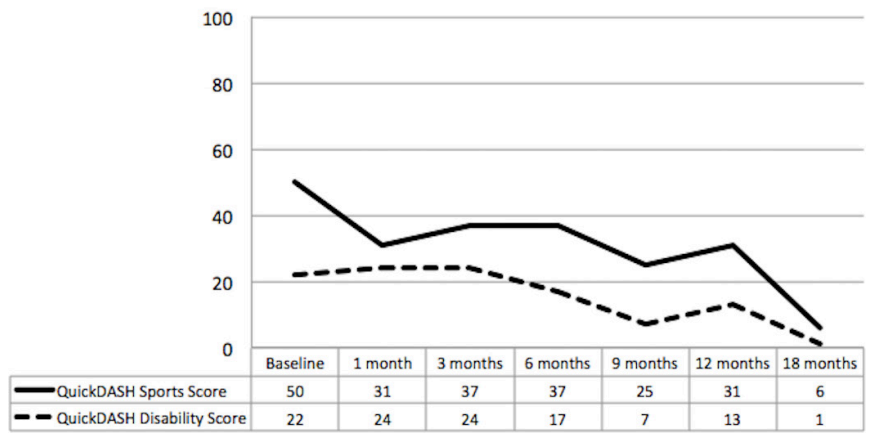

Figure 4 Quick disability of arm, shoulder and hand scores showing improvement in pain and function until completion of follow-up at 18 months. 
surgical distal clavicular excision (open or arthroscopic). While this technique has been shown to result in reproducible improvement in pain and function, it is not without complications which may include joint instability, shoulder weakness and possible anaesthetic complication.

Autologous MSC therapy has been increasingly studied in the treatment of symptomatic knee OA, although there are no studies on the use of MSC in small joints or those of the upper limb. ${ }^{18-20}$ Importantly, the observed potential benefit in knee OA may not be a reproducible finding in other joints.

In this single case study, the use of autologous AdMSC therapy in symptomatic AC joint arthropathy resulted in clinically significant pain, function and structural improvements. The procedure was well tolerated with only a mild and brief flare up in discomfort observed following MSC therapy.

Past research has observed the age of the cell donor to influence MSC cell senescence and differentiation capacity indicating that the patient's age may influence outcome of therapy. ${ }^{34} 35$ The benefit of autologous MSC therapy in an older population needs to be determined. Further, factors including joint instability and co-existant pathology such as rotator cuff pathology or gleno-humeral joint OA may additionally influence outcome.

The results presented in this case study suggest that AdMSCS may prove to be a suitable treatment for symptomatic AC joint or other small joint arthropathy which fails traditional conservative management prior to consideration of surgical intervention.

\section{Learning points}

- Acromio-clavicular (AC) joint pathology is an under recognised and a frequent cause of shoulder pain.

- Current conservative management of AC joint arthropathy and distal clavicular osteolysis (DCO) is limited and frequently ineffective.

- Surgical management of AC joint arthropathy or DCO through distal clavicular excision is reproducible in outcome but can be associated with complications.

- Autologous adipose-derived MSC therapy may offer a conservative alternative approach to AC joint pain management prior to consideration of surgery.

Acknowledgements The authors would like to acknowledge the following people for their contribution to the case study : Ellee Picken, Lesley-ann Kelly, Renee Castelluccio, Lucinda Kenihan and Melissa Grogan for assistance in data acquisition.

Contributors JF is a Sport and Exercise Medicine Physician and the treating physician of the patient presented in the case report. JF, JW, KS and AT were involved in the data acquisition, analysis of data and drafting of the report. JF, JW, KS and AT have read and approved the final manuscript. JF, JW, KS and AT agreed to be accountable for the article and to ensure that all questions regarding the integrity of the article are investigated and resolved.

Funding The authors have not declared a specific grant for this research from any funding agency in the public, commercial or not-for-profit sectors.

Competing interests JF is affiliated with Magellan Stem Cells and is a member of Magellan Stem Cells Clinical and Scientific Advisory Board. KS is affiliated with Magellan Stem Cells and is the Chief Scientific Officer of Magellan Stem Cells. AT is affiliated with Magellan Stem Cells.

Patient consent for publication Obtained.

Provenance and peer review Not commissioned; externally peer reviewed.

Open access This is an open access article distributed in accordance with the Creative Commons Attribution Non Commercial (CC BY-NC 4.0) license, which permits others to distribute, remix, adapt, build upon this work non-commercially, and license their derivative works on different terms, provided the original work is properly cited and the use is non-commercial. See: http://creativecommons.org/ licenses/by-nc/4.0/

\section{REFERENCES}

1 Zanca P. Shoulder pain: involvement of the acromioclavicular joint. American Journal of Roentgenology 1971;112:493-506.

2 Needell SD, Zlatkin MB, Sher JS, et al. MR imaging of the rotator cuff: peritendinous and bone abnormalities in an asymptomatic population. AJR Am J Roentgenol 1996;166:863-7

3 Menge TJ, Boykin RE, Bushnell BD, et al. Acromioclavicular osteoarthritis: a common cause of shoulder pain. South Med J 2014;107:324-9.

4 Brunet ME, Reynolds MC, Cook SD, et al. Atraumatic osteolysis of the distal clavicle: histologic evidence of synovial pathogenesis. A case report. Orthopedics 1986;9:557-9.

5 Flatow EL, Duralde XA, Nicholson GP, et al. Arthroscopic resection of the distal clavicle with a superior approach. J Shoulder Elbow Surg 1995;4():41-50.

6 Worcester JN, Green DP. Osteoarthritis of the acromioclavicular joint. Clin Orthop Relat Res 1968;58:69???74-74.

7 Pensak M, Grumet RC, Slabaugh MA, et al. Open versus arthroscopic distal clavicle resection. Arthroscopy 2010;26:697-704.

8 Basamania C, Wirth M, Rockwood Jr C, et al. Failed distal clavicle resections. Orthop Trans 1995-1996;19:355.

9. Blazar PE, lannotti JP, Williams GR. Anteroposterior instability of the distal clavicle after distal clavicle resection. Clin Orthop Relat Res 1998;348:114-20.

10 Cook FF, Tibone JE. The Mumford procedure in athletes. An objective analysis of function. Am J Sports Med 1988;16:97-100.

11 Shaffer BS. Painful conditions of the acromioclavicular joint. J Am Acad Orthop Surg 1999;7:176-88.

12 Arinzeh TL. Mesenchymal stem cells for bone repair: preclinical studies and potential orthopedic applications. Foot Ankle Clin 2005;10:651-65.

13 Barry FP, Murphy JM. Mesenchymal stem cells: clinical applications and biological characterization. Int J Biochem Cell Biol 2004;36:568-84.

14 Noël D, Djouad F, Jorgense C. Regenerative medicine through mesenchymal stem cells for bone and cartilage repair. Curr Opin Investig Drugs 2002;3:1000-4.

15 Caplan AI. Why are MSCs therapeutic? New data: new insight. J Pathol 2009:217:318-24.

16 Gardner OFW, Musumeci G, Neumann AJ, et al. Asymmetrical seeding of MSCs into fibrin-poly(ester-urethane) scaffolds and its effect on mechanically induced chondrogenesis. J Tissue Eng Regen Med 2017;11:2912-21.

17 Grigolo B, Lisignoli G, Desando G, et al. Osteoarthritis treated with mesenchymal stem cells on hyaluronan-based scaffold in rabbit. Tissue Eng Part C Methods 2009;15:647-58.

18 Jo CH, Lee YG, Shin WH, et al. Intra-articular injection of mesenchymal stem cells for the treatment of osteoarthritis of the knee: a proof-of-concept clinical trial. Stem Cells 2014;32:1254-66.

19 Vangsness CT, Farr J, Boyd J, et al. Adult human mesenchymal stem cells delivered via intra-articular injection to the knee following partial medial meniscectomy. J Bone Joint Surg Am 2014;96:90-8.

20 Vega A, Martín-Ferrero MA, Del Canto F, et al. Treatment of knee osteoarthritis with allogeneic bone marrow mesenchymal stem cells: a randomized controlled trial. Transplantation 2015;99:1681-90.

21 Im Gl, Shin YW, Lee KB. Do adipose tissue-derived mesenchymal stem cells have the same osteogenic and chondrogenic potential as bone marrow-derived cells? Osteoarthritis Cartilage 2005;13:845-53.

22 Peng $L$, Jia Z, Yin $X$, et al. Comparative analysis of mesenchymal stem cells from bone marrow, cartilage, and adipose tissue. Stem Cells Dev 2008;17:761-74.

23 Musumeci G, Mobasheri A, Trovato FM, et al. Biosynthesis of collagen I, II, RUNX2 and lubricin at different time points of chondrogenic differentiation in a $3 \mathrm{D}$ in vitro model of human mesenchymal stem cells derived from adipose tissue. Acta Histochem 2014;116:1407-17.

24 Freitag J, Ford J, Bates D, et al. Adipose derived mesenchymal stem cell therapy in the treatment of isolated knee chondral lesions: design of a randomised controlled pilot study comparing arthroscopic microfracture versus arthroscopic microfracture combined with postoperative mesenchymal stem cell injections. BMJ Open 2015;5:e009332

25 Freitag J, Li D, Wickham J, et al. Effect of autologous adipose-derived mesenchymal stem cell therapy in the treatment of a post-traumatic chondral defect of the knee. BMJ Case Rep 2017;79:bcr-2017-220852.

26 Zuk PA, Zhu M, Ashjian P, et al. Human adipose tissue is a source of multipotent stem cells. Mol Biol Cell 2002;13:4279-95

27 Goh BC, Thirumala S, Kilroy G, et al. Cryopreservation characteristics of adiposederived stem cells: maintenance of differentiation potential and viability. J Tissue Eng Regen Med 2007:1:322-4.

28 Martinello T, Bronzini I, Maccatrozzo L, et al. Canine adipose-derived-mesenchymal stem cells do not lose stem features after a long-term cryopreservation. Res Vet Sci 2011;91:18-24.

29 Dominici M, Le Blanc K, Mueller I, et al. Minimal criteria for defining multipotent mesenchymal stromal cells. The International Society for Cellular Therapy position statement. Cytotherapy 2006;8:315-7. 
30 Zhu Y, Yuan M, Meng HY, et al. Basic science and clinical application of platelet-rich plasma for cartilage defects and osteoarthritis: a review. Osteoarthritis Cartilage 2013;21:1627-37.

31 Dworkin RH, Turk DC, Farrar JT, et al. Core outcome measures for chronic pain clinical trials: IMMPACT recommendations. Pain 2005;113:9-19.

32 SooHoo NF, McDonald AP, Seiler JG, et al. Evaluation of the construct validity of the DASH questionnaire by correlation to the SF-36. J Hand Surg Am 2002:27:537-41.
33 Gummesson C, Atroshi I, Ekdahl C. The disabilities of the arm, shoulder and hand (DASH) outcome questionnaire: longitudinal construct validity and measuring selfrated health change after surgery. BMC Musculoskelet Disord 2003;4:11.

34 Szychlinska MA, Stoddart MJ, D’Amora U, et al. Mesenchymal stem cell-based cartilage regeneration approach and cell senescence: can we manipulate cell aging and function? Tissue Eng Part B Rev 2017;23:529-39.

35 Li J, Pei M. Cell senescence: a challenge in cartilage engineering and regeneration. Tissue Eng Part B Rev 2012;18:270-87.

Copyright 2019 BMJ Publishing Group. All rights reserved. For permission to reuse any of this content visit https://www.bmj.com/company/products-services/rights-and-licensing/permissions/

BMJ Case Report Fellows may re-use this article for personal use and teaching without any further permission.

Become a Fellow of BMJ Case Reports today and you can:

- Submit as many cases as you like

- Enjoy fast sympathetic peer review and rapid publication of accepted articles

- Access all the published articles

- Re-use any of the published material for personal use and teaching without further permission

For information on Institutional Fellowships contact consortiasales@bmjgroup.com

Visit casereports.bmj.com for more articles like this and to become a Fellow 